\title{
Erratum to: Evaluation of physical activity and its relationship to health-related quality of life in patients on chronic hemodialysis
}

\author{
Akihiko Katayama $\cdot$ Nobuyuki Miyatake $\cdot$ \\ Hiroyuki Nishi $\cdot$ Kazuhiro Uzike • Noriko Sakano • \\ Hiroo Hashimoto $\cdot$ Kiichi Koumoto
}

Published online: 7 February 2015

(c) The Japanese Society for Hygiene 2015

Erratum to: Environ Health Prev Med (2014)

19:220-225

DOI 10.1007/s12199-014-0380-z

The authors would like to correct the error occurred in the 'Result' section, of the original publication as below:

Among all patients on chronic hemodialysis, only physical activity over 4 METs on non-hemodialysis treatment days was a determinant factor of EQ-5D [EQ-5D scores $=0.300$ (physical activity over 4 METs on nonhemodialysis treatment days) $+0.695, r^{2}=0.181$, $p=0.0026]$.

The online version of the original article can be found under doi:10.1007/s12199-014-0380-z.

\footnotetext{
A. Katayama $(\varangle) \cdot$ N. Miyatake $\cdot$ N. Sakano Department of Hygiene, Faculty of Medicine, Kagawa

University, 1750-1, Miki, Kagawa 761-0793, Japan

e-mail: kata@med.kagawa-u.ac.jp

H. Nishi - K. Uzike · H. Hashimoto · K. Koumoto Innoshima General Hospital, Onomichi, Hiroshima 722-2323,

Japan
} 